\title{
CAPITAL INVESTMENT CRITERION FOR \\ BULK ELECTRICITY TRANSMISSION INFRASTRUCTURE: \\ A CONSUMPTION APPROACH
}

\author{
R.D. Smith and R.J.O. Joubert ${ }^{[1]}$ \\ ${ }^{[1]}$ Respectively MBL Student and Professor \\ UNISA Graduate School of Business Leadership \\ jouberjo@alpha.unisa.ac.za
}

\begin{abstract}
The primary technical function of an electric utility company is to supply electrical energy to its customers economically and at acceptable levels of reliability. The aspects of economics and reliability are however, competing constraints, since increased reliability of supply generally requires increased capital investment, which leads to higher prices for electricity.

Traditional capital budgeting criteria, such as positive net present value, have been found to inhibit sound economic capital investment decision-making within the bulk electricity transmission environment. It is submitted that the results of this investigation will enable the operators of bulk electricity transmission systems to match the level of investment in reliability related infrastructure, with customers' reliability preferences. To do this it is necessary to incorporate the economic valueof-service reliability to customers into the economic evaluation used by utility planners.
\end{abstract}

\section{GLOSSARY OF TERMS}

capital investment criteria, consumer surplus, cost-benefit analysis, cost of unsupplied energy, customer interruption cost, economics, economic evaluation, electricity, electrical energy transmission system, expected energy at nisk, expected energy not supplied, net economic benefit, reliability of electrical service. 


\section{INTRODUCTION}

The electric power industry faces planning problems which are characterised by a range of alternative supply-side and demand-side solutions, multiple conflicting objectives - economic, financial and service related - of the various stakeholders, pervasive uncertainty (such as load growth requiring long-term forecasts) that cannot be eliminated and, consequent risk that must be managed. It is imperative to ensure that money is not wasted on large and expensive construction projects when it is cheaper for the customer to reduce peak demand than for the utility to increase supply capacity.

\subsection{ELECTRICITY TRANSMISSION SYSTEM EXPANSION CRITERIA}

Electricity supply networks have traditionally been designed to be "firm" or "non-firm" by utilities all over the world. A non-firm system consists of the minimum number of components required to supply a specific load or consumer. If any one of the components is out of service it causes an interruption to the consumer(s) electricity supply for the duration of the component outage. Alternatively, a firm supply enables the utility to supply all or most of the load under component outage conditions in order to provide a suitable quality of supply (under equipment failure or maintenance conditions) in accordance with deterministic criteria. Due to the magnitude of the bulk loads (for example, large municipalities and factories) supplied, electricity transmission systems world-wide (in South Africa this means networks operated at the 220 kilovolt to 765 kilovolt level) have traditionally been designed and constructed as firm networks, because utilities have perceived the quality of supply (QOS) requirements of the large consumers of electricity to be very high.

\subsection{JUSTIFICATION OF REQUIRED TRANSMISSION INFRASTRUCTURE CAPITAL EXPENDITURE}

Well-known capital budgeting considerations, such as discounted cash flow techniques and present value calculations, are normally used by a broad spectrum of organizations when evaluating capital investment proposals. In the context of the electricity transmission business one would expect requested capital expenditure to be approved if it can be demonstrated that the proposed investment will show a positive net present value (NPV) after all expected future cash flows associated with the proposed investment are taken into consideration over the period that the new asset is expected to be in service. Typically, the following Fquation (1.1) could be considered appropriate for the required capital budgeting evaluation:

$$
\mathrm{NPV}_{\text {investment }}=\mathrm{PV}_{\text {incremental revenue }}-\mathrm{PV}_{\text {incremental costs }}
$$

where

$\begin{array}{lll}\text { Incremental Revenue } & = & \text { Incremental Electricity Sales x Applicable } \\ & = & \text { Tariff } \\ \text { Incremental Costs } & \text { Capital }+ \text { Cost to Generate Incremental Sales } \\ & + \text { Incremental Operating and Maintenance Costs }\end{array}$


The above investment decision-making procedure is suitable for evaluating non-firm network expansion because the associated capital expenditure can be compared to significant incremental sales. However, as previously mentioned, transmission systems are essentially firm networks that can normally supply the peak load demanded with at least one component out of service. This exposes a shortcoming of the positive NPV investment criterion because it is not able to provide suitable indication of the level of network redundancy required to supply the increasing load (that is, firm versus non-firm system configuration). The reason for this is that all capital expenditure associated with the duplicate or "redundant" network component(s) cannot be evaluated against incremental energy sales under normal, system healthy conditions. It is only during network component outages that the duplicate system may realise incremental energy sales, depending on the loading on the system at the time of the contingency. These outage conditions are typically of short duration and have a low probability of occurrence.

In order to measure the effectiveness of investments in redundant network components, it is necessary to perform a complete probabilistic analysis of the expected performance of an alternative non-firm supply system. It can be demonstrated that a typical bulk electricity transmission system would have to be non-firm (with the associated reduction in the quality of supply provided) before any new transmission expansion projects could be justified and approved, by conducting a realistic reliability assessment of alternative firm and non-firm supply networks using probabilistic techniques. Clearly, existing capital investment decision-making criteria such as positive NPV (which may be suitable for new non-firm, sub-transmission or reticulation networks) are not suitable for transmission expansion because they lead to levels of supply reliability which will most likely be unacceptable to bulk consumers of electricity.

One can therefore summarise the main study area of this paper as follows:

- How does the utility determine the transmission system component redundancy required to meet the quality of supply desired by the bulk electricity consumer?

- Should the power company consider the financial returns to the utility alone and/or assign some value to the external customer benefits that can be ascribed to the proposed new transmission infrastructure investment, when justifying the required capital expenditure?

\section{BULK ELECTRICITY TRANSMISSION SUPPLY AND DEMAND CURVES -}

\section{PART I: The Intricacies of Power Company Cash-flow NPV Calculations}

This section is intended to demonstrate, from an economic point of view, why DCF techniques and the results of PV calculations (taking only utility cash flows into consideration) do not provide meaningful information in terms of transmission infrastructure investment decision-making.

Let us consider the supply (represented by short-run marginal supply costs - $\mathrm{SRMSC}_{0}$ ), demand $\left(\mathrm{D}_{0}\right)$ and average total cost $\left(\mathrm{ATC}_{0}\right)$ curves for bulk electricity transmission at a particular supply point (or substation) on the network that is well established and supplying a load that marginally exceeds the firm capacity of the installed substation equipment and supporting transmission lines. 
In other words, while all components are in service, no demand for electricity is curtailed or interrupted, but with any single element out of service, supply is curtailed to the quantity that equals the firm rating of the supply system. This situation is depicted in Figure 2.1a below, which expands the bottom right hand corner of the complete supply and demand curves for illustrative purposes. Some important aspects to take cognizance of in Figure 2.1a are:

- $\quad$ Output $\mathrm{Q}$ is restricted (from $\mathrm{Q}_{\mathrm{opt}}$ - which would be the total amount of energy demanded and supplied if no components are ever out of service, to $\mathrm{Q}_{\text {ailo }}$ - which is the quantity supplied under network component outage conditions) through poor system performance (reliability or quality of supply) and not as a result of a price increase, or the lack of firm capacity under system healthy conditions.

- $\quad$ Furthermore, Q Qail0 can be located anywhere between 0 (zero) and Qfailo depending on the extent and nature of the system outage condition because, although the probability of occurrence is very small, two or more elements could fail simultaneously.

- The slight upward slope of the $\mathrm{SRMSC}_{0}$ line is caused by the non-linear increase in transmission system losses per $\mathrm{kWh}$ delivered to the customer.

- We assume for the purposes of this discussion that the demand curve $\mathrm{D}_{0}$ has a downwardsloping, linear function.

- $\quad$ The producer profit generated at the substation is equal to:

Area ACDF - Area BCDE x Probability(System 0 constrained condition)

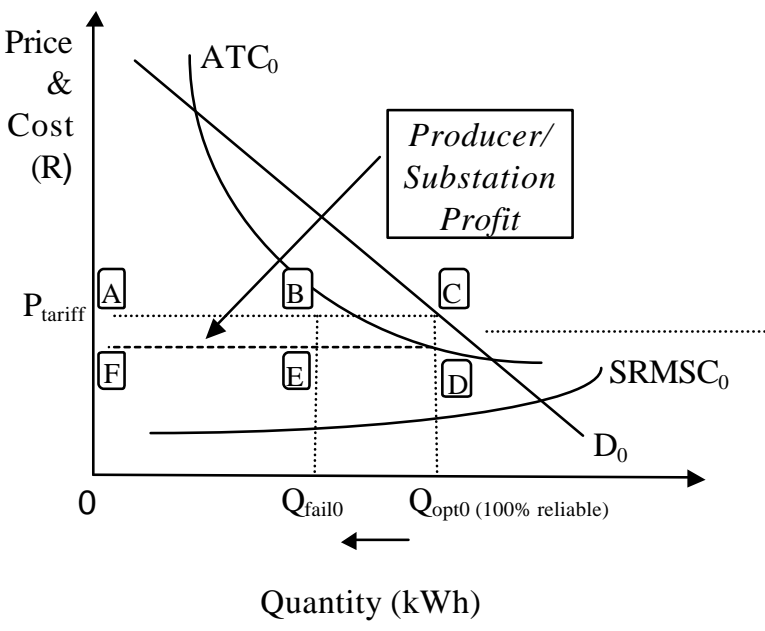

Figure 2.1a: Supply, Demand and Costs prior to System Expansion

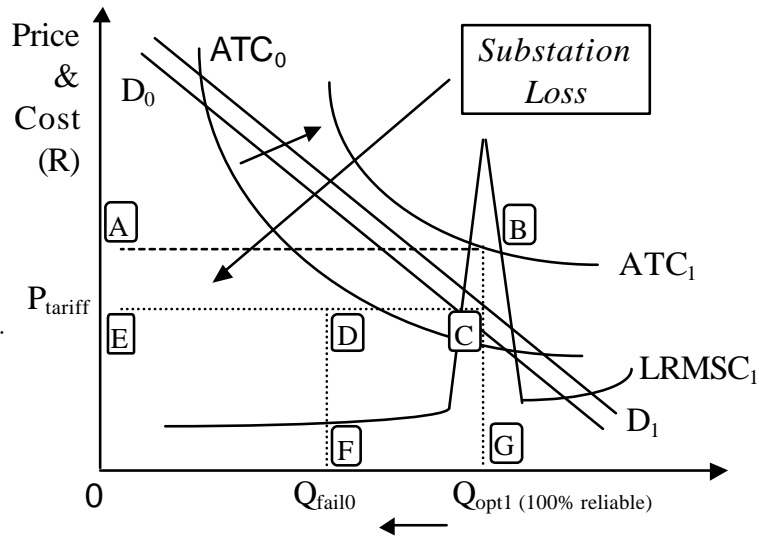

Quantity (kWh)

Figure 2.1b: The Impact of System Expansion Investments

As the quality of supply provided to consumers deteriorates over time due to ageing of equipment (causing more frequent component failures) and increasing demand (say from $\mathrm{D}_{0}$ to $\mathrm{D}_{1}$ ) on the particular transmission system, new capacity must be added to the supply system. Owing to economies of scale, capacity additions to transmission systems tend to be large and long-lived, resulting in block investments which cause sharp increases (or "spikes") to the long-run marginal supply cost - represented by curve $\mathrm{LRMSC}_{1}$ in Figure $2.1 \mathrm{~b}$ above. Once the capacity of the transmission network has been increased (for example, following the commissioning of an addition 
line and/or transformer), the $\mathrm{LRMSC}_{1}$ is reduced again to a much lower level. However, this capital injection has the effect of significantly increasing the average total costs (see curve $\mathrm{ATC}_{1}$ in Figure 2.1b) above the price, because large fixed cost have to be amortized over proportionately fewer units of output.

It is important to note that the level of electricity tariff charged (at the supply point in question) subsequent to the capital investment for the capacity addition remains constant. If we assume that the capital investment has the effect (benefit) of eliminating the most severe single component outage condition that would have constrained kilowatt hour output to Q Qail prior to the capacity addition (ignoring all other possible single or multiple contingency conditions), then we can calculate incremental sales revenue to be (as shown in Figure 2.1b):

$\begin{aligned} \text { Incremental Revenue }= & \begin{array}{l}\text { Area DCGF } \times \text { Probability }\left(\text { System }_{0} \text { constrained }\right. \\ \text { condition })\end{array} \\ = & \begin{array}{l}\text { Tariff }(\mathrm{c} / \mathrm{kWh}) \times \Delta \text { Quantity Supplied }(\mathrm{kWh}) \\ \mathrm{X} \text { Probability }\left(\text { System }_{0} \text { constrained }\right)\end{array}\end{aligned}$

But, as is evident from the illustration above, the incremental total costs have increased by an amount:

Area $\mathrm{ABCQ}_{\text {opt1 }} 0$ (in Figure 2.1b) - Area $\mathrm{FEDQ}_{\mathrm{opt0} 0} 0$ (in Figure 2.1a)

which is far greater than the incremental revenue (especially because the incremental costs are not multiplied by the typically low probability of the system being in any constrained condition). Hence, the supply authority profit previously generated at the particular substation has been transformed into a substation loss situation because of the additional infrastructure. This is why the requested capital expenditure would not be approved.

\section{PURPOSE OF THIS INVESTIGATION}

The fact that most transmission system expansion proposals consistently produced negative NPV results (because of the configuration of the supply network and the capital intensive nature of transmission system capacity additions), initiated the search for a more meaningful capital investment evaluation methodology. Khatib[13] studied the analysis of expected financial and economic performance of a project in the electricity supply industry, which is necessary before a new investment is undertaken. Financial evaluation considers the money aspect of the project (financial profitability to investors) and requires that financial costs and benefits be quantified. Economic evaluation ventures beyond this and attempts to relate the project to the national economy (economic, social and environmental implications). These latter considerations are normally called "externalities" because they involve issues that will not appear as benefits on the balance sheet of the investing organisation. In this context, externalities that should be considered in capital investment evaluations are the benefits that consumers derive from receiving a good quality of electricity supply. According to Khatib[13] it is not sufficient to evaluate the financial side alone. This is essentially what distinguishes economic cost-benefit evaluation methods from financial appraisals of smaller project investments. 
There has been growing consensus in the available economic literature that the current electricity quality of supply or, reliability targets are above the social optimum (Andrews[2]). However, it is also understood that electricity producers cannot simply reduce reliability levels without expecting to elicit some form of protest from their customers (at least from some types or classes of electricity consumers). This uncertainty with regards to the most acceptable reliability of service has initiated the re-evaluation and refinement of the cost-benefit analysis techniques that have been developed to date. Investments related to the provision of electric service reliability should be carefully evaluated with regards to their cost and benefit implications (Sanghvi[18]). An explicit cost-benefit analysis provides the basis for answering the economic question: How much reliability is adequate from the customer's perspective. The essence of this approach is the recognition of the fact that from a consumer's perspective, the total cost of electric service consists of two components: cost of service received and, cost of service interruptions. Thus, consumers are best served when this total cost is minimised.

\section{INTRODUCING THE CONCEPT OF CUSTOMER INTERRUPTION COSTS}

The electricity supply industry operates a very complex and highly integrated power system. Failures of any one component can cause interruptions, which range from inconveniencing a small number of local residents, to a major and widespread catastrophic disruption of supply. The impacts of electric power shortages, if they materialize therefore, can range from inconvenience and discomfort to social deprivation and severe economic loss. Experience gained from the blackouts of the Northeast USA and Ontario, Canada; the city of New York, the entire French electricity supply system and the Western United States in 1965, 1977, 1978 and July 1996 respectively, serves to heighten the consequences of potential electricity shortages in people's minds (Sanghvi and Limaye[15], Sanghvi[18]). The short-term estimated cost of the New York City blackout was US \$350 million (Douglas[7]). In the latter instance mentioned above, service was interrupted to over two million customers in 14 States, two Canadian provinces and the northern portion of Mexico. A total of 11 860 megawatts (MW) of load was disrupted. Similar major electrical energy supply interruptions have occurred in South Africa. For example, the entire Cape Province and Namibia experienced an electricity supply interruption in November 1990. Further blackouts occurred in the Southern and Western Cape in December 1995 and June 1996. And, even more recently, a number of consumers in Namibia and the Cape Province experienced supply problems because load shedding was necessary to avert total system collapse when demand exceeded available generation and transmission supply capability during October 1998. The economic impact of these outages is not only restricted to loss of revenue to the utility or loss of energy utilisation by the customer. In order to estimate the true costs, one should also consider indirect costs imposed on society and the environment due to the outage (Allan and Billinton[1]).

Electric power supply is the economic foundation of a modern industrialized country. Without the motive power of electricity, modern industries have no means of production and citizens face tremendous inconvenience in their daily lives (Chen and Vella[6]). Potentially, the more dependant society is on electricity, the higher the interruption costs imposed on customers are likely to be. Supply interruption or outage costs represent the economic consequences of electric service 
curtailments to the customer. Outage costs are commensurate with a customer's dependence on electricity and to what extent production activities or other impacted services can be recovered or re-scheduled subsequent to an outage and vary significantly depending on the particular attributes of the outage. The cost of an electrical supply interruption to a consumer is a function of the time of day and season at which the disturbance occurs; the duration of outage; the frequency of the outages, voltage depressions, frequency fluctuations and other quality degradation; the nature of activities affected; the degree to which the activities affected depend on electricity; the availability of a backup power source; the ability to resume the affected activity normally after power is restored; whether advance warning of an impending outage is provided to end-users and, a host of other determinants. Consequently, the cost of an outage is different for each consumer within a class and between classes of consumers (Sanghvi and Limaye[15], Sanghvi[18]).

The economic costs of power interruptions (total outages) or power curtailments (partial outages), can be identified as comprising of two components: short-term outage costs and long-term adaptive response costs. Sanghvi[17] refers to the sum of these components as shortage costs. Short-term outage costs are the costs incurred by consumers - both direct and indirect - given the consumers' capital investment that is associated with the aforementioned equipment and facilities, at the time immediately before the supply disruption. Direct shortage costs encompass the immediate economic loss of productive activity. Such losses include absolute loss of production, delayed production, spoiled materials, damaged equipment, the loss of data or output from a computer system and, the opportunity cost of idle resources (Chen and Vella[6]). Indirect shortage costs cover, for instance, the loss of future market share if products cannot be delivered to the market on time.

Furthermore, it is suggested by Sanghvi[17] that customers generally develop certain expectations (based on their respective past experiences) about the reliability of future electricity service. Some customers may then find it cost effective to take one or more mitigating actions to cope with future service curtailment and/or quality degradation, depending on these expectations. These potential reductions in future short-term outage costs will therefore, come at the present day expense (which could entail certain capital and/or operating expenditure) of the chosen mitigating measure(s). Such costs are referred to as long-term adaptive response costs (Sanghvi[17]). Typical long-term mitigating measures include the installation of standby (emergency) generation. Dutkiewicz[8] states that: for the consumer to whom electricity is vitally important, i.e. a hospital or computer bureau, the cost of electricity not supplied can be equated to the cost of the alternative energy sources, such as stand-by generators, which the organization is prepared to put in by itself".

\section{REVIEW OF COST-BENEFIT ANALYSIS MODELS PREVIOUSLY PRESENTED IN AVAILABLE ECONOMIC LITERATURE}

As mentioned during the introduction to this paper, customer preferences for service reliability are typically not considered in deterministic system planning criterion that are applied to establish firm transmission network. As a result, the cost and level of service reliability supplied by the utility may differ from what customers desire and for what they are willing to pay. If so, the reliability level provided is not economically efficient for either the utility or the customer. The reliability optimisation 
approach presented below adds an entirely new dimension to the traditional process of network expansion planning. In the new approach, the reliability level is also a variable to be optimised. The basic definition of the socially optimal reliability level has not changed since Shipley, Patton and Denison first explicitly stated in 1972 that: "presumably, the total electric power related cost to the nation would be minimized for that value of service availability which minimizes the sum of (i) utility system annual owning and operating costs and, (ii) the total annual cost of service interruptions" (Andrews[2]). A similar view is expressed by Hobbs, Rouse and Hoog[11] as follows: "when comparing the economics of alternative portfolios of supply and demand-side resources, utility planners should consider not only costs but also effects upon the benefits or "value" that electricity consumers receive". Moreover, "system planners should evaluate proposals for contemporary reinforcement and refurbishment schemes not only from the point of view of changes in frequency and duration of interruptions and the costs involved i.e. the utility perspective, but should also consider the customer benefits accruing from the changes i.e. the customer perspective" (Kariuki and Allan[12]).

By explicitly introducing the notion of shortage or outage costs in welfare maximising models of electricity consumption, it has been shown (Munasinghe[14]) that the optimal conditions for price and capacity levels must be simultaneously satisfied. In this context, determining the optimal capacity level is equivalent to establishing the optimal level of reliability (or lower consumer outage costs) and vice versa. The optimal price is the marginal cost of supply. Maximum net benefits are realised when price equals marginal cost.

The optimal reliability (capacity) level is defined as the point at which the marginal cost of increasing reliability is exactly equal to the corresponding reduction in marginal outage cost of consumers. Reliability (Rel) is a variable to be optimised in the framework to determine the optimal investment (or reliability) level for a bulk electricity transmission system. This approach subsumes the traditional least-cost investment planning criterion of meeting a given demand forecast at a fixed or target reliability level. Changes in reliability have several important economic consequences. First, as quality increases, the costs to the supplier (SC) of building, operating and maintaining the system also increase. On the other hand, as reliability improves, the shortage costs and inconvenience suffered by consumers (CC) due to disruption in supply (including outages and the effects of voltage depressions) will decrease. An improvement in supply quality is also likely to raise the consumers' expectation regarding the future level of reliability $\left(\operatorname{Re}_{\text {exp }}\right)$ which, in turn, is likely to induce increased electricity demand which provides additional net benefits of consumption (Munasinghe[14]). Changes in Rel $_{\text {exp }}$ may also affect customer outage costs as consumers adapt their behaviour patterns to reduce their shortage costs. Thus by increasing reliability, it will be possible to trade off the higher system costs against the decrease in customer outage costs and net benefits of induced demand.

The goals of maximizing economic benefits and enhancing economic efficiency can be achieved simultaneously if the optimal level of reliability is defined by a level at which the marginal cost of increasing reliability is equal to the marginal increase in total economic benefits, less the marginal change in customer shortage costs. The starting point for the cost-benefit analysis is the maximisation of some social welfare function. According to Sanghvi[17], "a frequently used function is the sum 
of consumer surplus plus total revenues less total costs, that is, the sum of consumer and producer surplus". This function can be stated as:

$$
\mathrm{NEB}(\mathrm{D}, \mathrm{Rel}) \quad=\quad \mathrm{WTP}(\mathrm{D}, \mathrm{Rel})-\mathrm{SC}(\mathrm{D}, \mathrm{Rel})
$$

WTP denotes the customer willingness-to-pay to consume a quantity D of electricity at reliability Rel and, SC denotes total system cost. It is assumed that electricity demand D is a function of the reliability "Rel". Alternatively, the net benefits of electricity consumption (NB) may be written as (Munasinghe[14]):

$$
\mathrm{NB}(\mathrm{D}, \mathrm{Rel})=\mathrm{TB}(\mathrm{D})-\mathrm{SC}(\mathrm{D}, \mathrm{Rel})-\mathrm{CC}\left(\mathrm{D}, \mathrm{Rel}, \mathrm{Rel}_{\mathrm{exp}}\right)
$$

where TB is the total benefit of consumption and is a function of demand (D), as are SC and CC. In addition, SC and CC are also functions of Rel and $\mathrm{Re}_{\mathrm{exp}}$ as indicated in the formulation above. The necessary first-order condition for a power system expansion proposal to be optimal is (Sanghvi[17]):

$$
\frac{\mathrm{dNEB}}{\mathrm{dRel}} \quad=\quad 0 \quad \text { or, } \quad \frac{\mathrm{dWTP}}{\mathrm{dRel}}=\frac{\mathrm{dSC}}{\mathrm{dRel}}
$$

and (Munasinghe[14]):

$$
\begin{aligned}
\frac{\mathrm{dNB}}{\mathrm{dRel}} & =\frac{\mathrm{dTB}}{\mathrm{dRel}}-\frac{\mathrm{dSC}}{\mathrm{dRel}}-\frac{\mathrm{dCC}}{\mathrm{dRel}}=0 \\
\text { or } \frac{\mathrm{dSC}}{\mathrm{dRel}} & =\frac{\mathrm{dTB}}{\mathrm{dRel}}-\frac{\mathrm{dCC}}{\mathrm{dRel}}
\end{aligned}
$$

where

$$
\begin{aligned}
& \mathrm{dSC} / \mathrm{dRel}=\quad \begin{array}{l}
\text { the total change in supply costs due to variations in the actual } \\
\text { supply quality } \\
\mathrm{dCC} / \mathrm{dRel}= \\
\mathrm{the} \text { total change in customer outage costs due to variations in } \\
\text { the actual supply quality }
\end{array} \\
& \begin{array}{l}
\text { the change in total benefits caused by the induced demand } \\
\text { changes due to variations in Rel } \\
\text { changes in Rel }
\end{array}
\end{aligned}
$$

The above equations simply states that the optimal level of reliability is characterized by a point at which the marginal increase in willingness-to-pay due to a marginal change in reliability, is exactly offset by the corresponding marginal change in system fixed and variable costs. To maximise the net benefits of electricity consumption, the quality of supply should be increased up to a point where the marginal increase in system costs is equal to the marginal decrease in the costs of poor supply quality, plus the increase in the benefits of the induced demand. These marginal costs and benefits 
include both the direct effects of changes in Rel and, the indirect effects due to variations in Rel $_{\text {exp }}$ and D.

Similar models are also presented by Valtorta and Manzoni[21], Andrews [2], Kariuki and Allan[12], Allan and Billinton[1] and Billinton and Li[3].

\section{BULK ELECTRICITY TRANSMISSION SUPPLY AND DEMAND CURVES -}

\section{PART II: Establishing a Linkage with the Cost-Benefit Economic Analysis}

This section is intended to follow on from that in Section 2 to demonstrate the impact of the economic cost-benefit model(s) presented above, in the context of supply, demand and cost curves as they apply to bulk electricity transmission systems. We recall from Section 2 that the only benefit that could be ascribed to the power company as a result of a possible capacity addition was the incremental revenue, indicated by area DCGF in Figure 2.1b (repeated here in Figure 6.1 for convenience sake) less incremental operating costs and that most transmission infrastructure investment opportunities would be rejected if the utility benefits alone were taken into consideration during the proposal evaluation. The most significant difference between the traditional "positive NPV' investment criterion and the economic cost-benefit analysis model(s) presented in Section 5 is that the incremental consumer surplus (not a utility cash-flow) should also be accounted for when evaluating potential bulk electricity transmission system investments. The incremental consumer surplus, which is equivalent to the reduction in customer outage costs as a results of the capacity addition, is indicated by the area HDC (bounded by the $\mathrm{D}_{1}$ demand curve) in Figure 6.1 below. On the first unit of purchase the consumer realises a monetary gain, surplus, equal to the area $\mathrm{P}_{1} \mathrm{AIP}_{\text {tariff. }}$. On the second unit the surplus is equal to BCHI Rands and so on, yielding a total willingness-to-pay (consumer surplus) for the normal consumption of $\mathrm{Q}_{\text {ariff }} \mathrm{kWhs}$ equal to the area $\mathrm{P}_{1} \mathrm{EP}_{\text {tariff }}$ Rands. "When payments for energy (price $x$ quantity) are subtracted from the integral of the demand curve, the result is a measure of net value called consumer surplus" (Hobbs, Rouse and Hoog[11]). To reiterate therefore, the reduction in customer outage costs should be added to the resulting incremental revenue when evaluating the benefits of transmission system capacity additions in the future. The consumer surplus associated with electricity consumption can best be described with the assistance of Figure 6.2 below which illustrates a demand function (representing the quantity demanded at each price level) for electricity in given 4 hour period.

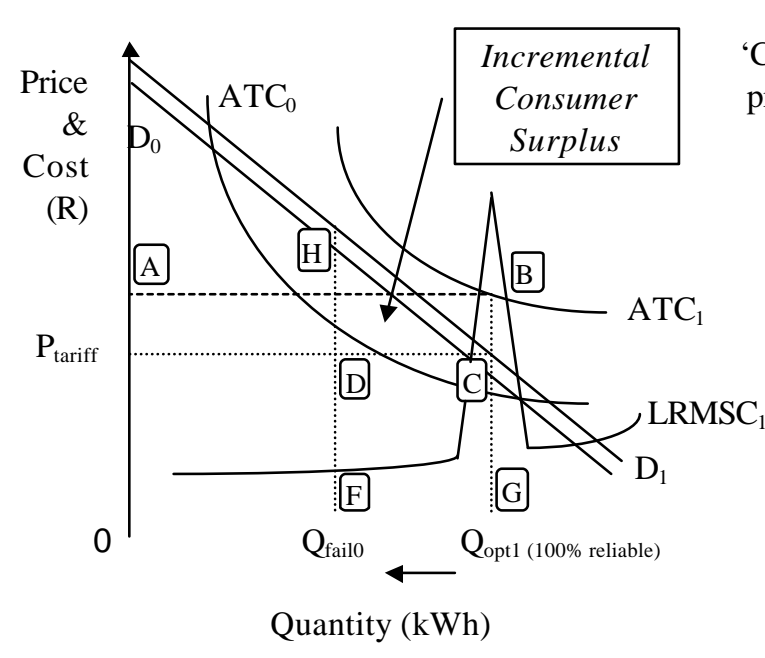

Quantity (kWh)

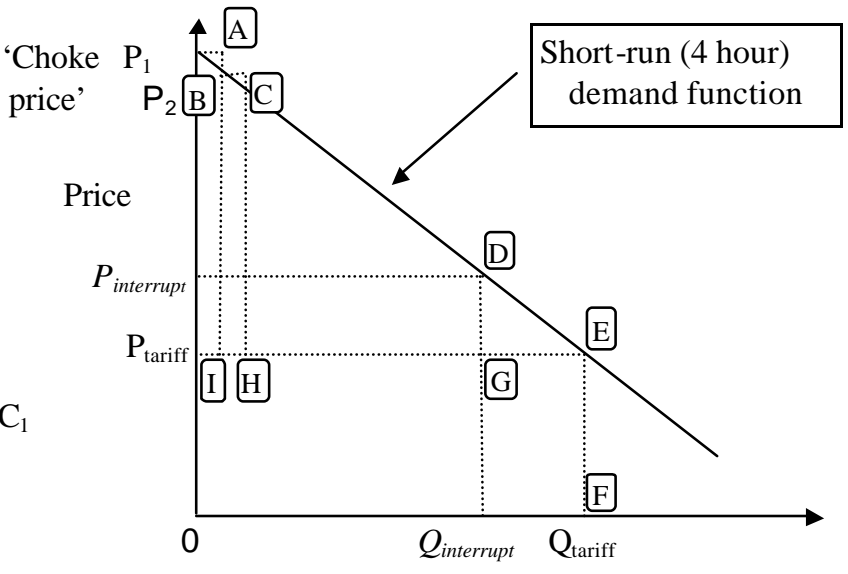

Electricity consumption in a given four hour period $(\mathrm{kWh})$ 

Figure 6.1: $\begin{aligned} & \text { Incremental Consumer Surplus } \\ & \text { to be Included }\end{aligned}$

\section{Figure 6.2: Consumer Surplus Loss During a Four Hour Outage (Sanghvi[16])}

The reduction in consumer surplus due to a supply interruption can be used to estimate customer outage costs because, embedded in the demand function for electricity at various times of the day, season and year, is information about the consumer's willingness-to-pay for each unit of electricity consumption in that period (Sanghvi[16]). The price the consumer is willing to pay for electricity reveals information about the lost value when electricity is unavailable due to a power interruption. This willingness-to-pay depends on the degree to which the consumption of each unit can be deferred, that is, substituted, to another hour. If in certain hours (for example, during the rolling process of flat coil steel manufacture, or, during one's favourite TV program), a large part of that hour's consumption is considered essential (deferrable, but with high associated costs), then this information is revealed by the demand function being more inelastic during those hours. Consequently the consumer surplus loss - which is equivalent to the consumer's willingness-to-pay to avoid a total outage in that hour - is larger (Sanghvi[16]).

In implementing the consumer surplus methodology to establish customer outage costs, care must be taken to ensure that such calculations are based on appropriate, short-run, set of demand functions. Otherwise the estimates obtained could grossly under- or over-estimate the true willingness-to-pay (Sanghvi[16]). Demand functions be estimated for the time period of the duration of the outage, hourly demand functions for one hour interruptions, two hour demand functions for two hour outages and so on.

The above section has hopefully succeeded in providing the conceptual linkages between the economic cost-benefit planning model(s) presented in Section 5 above and the more familiar supply, demand and cost curves that are often used to illustrate fundamental principles in the field of economic study. However, that the magnitude of the envisaged incremental consumer surplus or, reduction in customer interruption costs, have not been quantified in a manner suitable for use in the aforementioned transmission system reliability optimization models. Nevertheless, the actual measurement of customer interruption costs will be discussed in more detail in Section 8 of this paper.

\section{PROPOSED ECONOMIC MODEL FOR TRANSMISSION SYSTEM CAPITAL INVESTMENT DECISION-MAKING}

We recall from Section 5 that: 
(1) The optimal conditions for price and capacity levels must be simultaneously satisfied when customer interruption costs are explicitly introduced in welfare maximising models of electricity consumption (Munasinghe[14]).

(2) An improvement in supply quality is likely raise the consumers' expectation regarding the future level of service reliability which, in turn, is likely to induce increased electricity demand which provides additional net benefits of consumption (Munasinghe[14]). Under these conditions, the total benefits of consumption will be an increasing function due to the effects of induced demand.

This may be interpreted more clearly using Figure 7.1 below, where customer interruption costs CIC and supply costs to the utility USC are shown as decreasing and increasing functions of quality of supply (reliability), respectively. The total cost curve is defined by TC $=$ USC + CIC. TB is also an increasing function due to the effects of induced demand. The term CIC therefore, should be interpreted as the remaining short-term unavoidable customer interruption costs, arising from the difference between actual and expected reliability levels. The optimal value of quality of supply indicated in the figure $\left(\mathrm{Rel}_{\mathrm{opt}}\right)$ is where the marginality conditions in Equation 5.4 above are satisfied. At this point net benefits, NB = TB - TC are maximised (Munasinghe[14]).

However, it is recognised that electricity tariffs are related to average rather than marginal costs and are not readily subject to change. It is also acknowledged that the simultaneous optimisation of price and capacity is a theoretical ideal. Furthermore, it is exceptionally difficult to gauge the additional net benefits of consumption aute induced demand without available empirical data and/or an exhaustive iterative process. Thus from a practical point of view, it is suggested that:

(1) The joint price and system reliability optimisation be uncoupled in the current environment of relatively "fixed" tariffs.

(2) The effects of induced demand be ignored to determine the 'optimal' level of electrical service reliability.

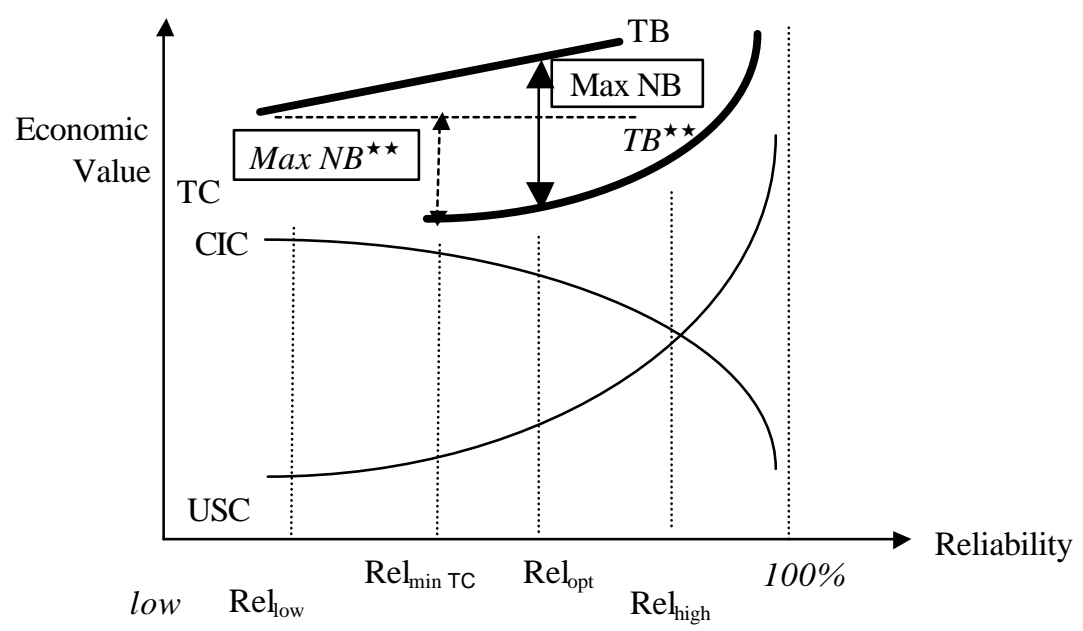

Figure 7.1: $\quad$ Optimal Transmission System Reliability (adapted from Munasinghe[14]) 
If the effects of induced demand are ignored and total benefits are independent of reliability in the model proposed by Munasinghe[14] (refer to the horizontal total benefits curve TB ${ }^{\star \star}$ in Figure 7.1), then maximising net benefits is equal to minimising total costs TC and the desired quality of supply is indicated by $\mathrm{Rel}_{\min } \mathrm{TC}$. If the Munasinghe[14] model is further constrained such that both demand (D) and the target reliability (Rel) were assumed to be fixed, then maximising NB would reduce to simply minimising the costs of supply (SC), which is the conventional and most commonly encountered system planning criterion: least-cost (to the utility) system expansion.

The proposed capital investment decision-making model is therefore intended to minimize the total cost of bulk electricity transmission to the partnership consisting of Eskom and the consumers who benefit from the new transmission infrastructure or, proposed network change. The optimum level of transmission system reliability would therefore not simply be realized by the leastcost supply option to the electricity utility. The proposed criterion states that "new transmission infrastructure or assets should be constructed and commissioned only when the extra annual costs incurred by Eskom for owning and operating the assets are less than the annual savings to the consumers, because power supply failures are expected to be less frequent and/or shorter in duration when the proposed infrastructure is part of the system" (compared to the situation where the infrastructure or asset has not been built).

(A) The extra costs incurred by Eskom for owning and operating new transmission infrastructure are:

The sum of (i) the equal annual cost of the capital invested in the new infrastructure and

(ii) the extra operating and maintenance costs caused by the new transmission infrastructure or asset(s);

less

(iii) the savings in transmission losses due to the new asset(s);

less

(iv) the extra income (revenue - incremental generation cost) resulting from additional sales because the interruptions of supply are less frequent and of shorter duration.

(B) The annual savings to the consumers because the new infrastructure is part of the transmission system include:

(i) all the consumer cost reductions resulting from the improved quality of supply.

The extra costs incurred by the power utility can be determined from straightforward engineering and economic considerations. The equal annual charge associated with required capital expenditure depends upon the real discount rate and the number of years over which the investment is to be recovered (commonly, over the average expected economic life of the proposed asset(s)). Refer to Heck[10] and Stoll[19] for the recommended capital recovery formulae in this regard. The extra operating and maintenance costs are in the first approximation a fixed percentage of the value of the plant (typically $0,5 \%$ per annum for lines and $2 \%$ to $3 \%$ per annum for substations) but are normally not incurred during the first year of operation and; the savings in transmission losses can be 
calculated from customer demand information, power system analysis studies and should be valued at the incremental cost of generation. To estimate the extra utility income resulting from additional sales (because interruptions are less frequent and shorter in duration), it is necessary to know the performance of the plant and to combine this performance with the load profile of the consumers, the appropriate tariff and the cost to generate the incremental energy sales and associated system losses, using probability techniques.

The benefits derived by the consumers are more difficult to assess. First, one must calculate the reduction in energy not supplied due to the improvement in quality of supply, i.e. the reduction in interruptions, voltage depressions, harmonics, etc. and then value this at the cost to consumers of energy not supplied. The calculations to assess the improved performance of the system are the same as for the calculation of the extra sales volume to Eskom (last item under "A"). On the other hand, the cost of energy not supplied (including the cost due to voltage depressions) is a function of the electrical load and particular interruption characteristics as mentioned in Section 4 above. Since the people who are the most familiar with this are the consumers themselves, this information can best be obtained via surveys.

\subsection{THE CORRECT TIMING OF THE PROPOSED INVESTMENT}

Theoretically, the comparison between the elements described under "A" and "B" in the Sub-section above should be done every year that the new asset is in service and, the present value net benefits of consumption calculated using Equation 7.1 (Munasinghe[14]):

$$
\mathrm{PV}(\mathrm{NB}) \quad=\quad \sum_{\mathrm{t}=0}^{\mathrm{T}}\left[\mathrm{TB}_{\mathrm{t}}\left(\mathrm{D}_{\mathrm{t}}\right)-\mathrm{SC}_{\mathrm{t}}\left(\mathrm{D}_{\mathrm{t}}, \operatorname{Re}_{\mathrm{t}}\right)-\mathrm{CC}\left(\mathrm{D}_{\mathrm{t}}, \operatorname{Rel}_{\mathrm{t}}\right)\right] \div(1+\mathrm{r})^{\mathrm{t}} \ldots . .
$$

where $\mathrm{T}$ is the planning period, $\mathrm{r}$ is the appropriate discount rate and other abbreviations are defined as before. In practice however, this is normally not necessary, because it is rare to have loads which are decreasing and, investments to increase the capacity of the transmission system would not be undertaken if this was expected to be the case. Under normal circumstances, it is only necessary to determine the first year in which " $A$ " is less than " $B$ " because we know that every single year thereafter condition "A" < "B", will be even more satisfied. Therefore, under increasing load conditions, the proposed capital expenditure decision-making criterion provides an indication of the optimal time at which to invest in and commission new transmission infrastructure. A similar approach is presented by Gauld[9].

In the following Sub-section, the various elements of the decision-making model will be quantified.

\subsection{PROPOSED INVESTMENT CRITERION EQUATIONS}

The economic cost-benefit or, least-total cost investment criterion equation to be satisfied can be expressed as follows: 
Value of Improved Quality of Supply to Customers > Cost to Provide the Improved

Quality of Supply

From equation (7.2) it is evident that if the value of the improved quality of supply to the customer is less than the incremental cost to the Transmission Company, then the Transmission Company should not invest in the new infrastructure or other proposed network changes. Equation (7.2) can be stated differently as;

Value (in Rand/kWh) x Reduction in Amount of Energy Not Supplied to Consumers $(\mathrm{kWh})>$ Cost to Enhance the Quality of Supply Provided by the Power System (Rand)

where

The Reduction in Expected Energy Not Supplied (EENS) to Consumers

$=$ EENS with Existing Network - EENS with Proposed Network Changes

with the reduction in EENS relating to all aspects of improved QOS (not only fewer power interruptions) and, the reduction in EENS calculated on a probabilistic basis.

EENS $=$ EEAR $\times \mathrm{P}(\mathrm{f})$

where

\begin{tabular}{|c|c|c|}
\hline EEAR & $=$ & $\begin{array}{l}\text { Expected Energy at Risk before the addition of the new infrastructure or } \\
\text { other proposed network change. It is equal to all the energy above the } \\
\text { rating of the existing firm network (refer to the discussion of the load } \\
\text { duration curve in Section } 7.3 \text { below). }\end{array}$ \\
\hline$P(f)$ & $=$ & $\begin{array}{l}\text { Probability that the system is constrained through one or more } \\
\text { components (primary or secondary equipment) being out of service. This } \\
\text { probability is a function of the performance of the plant. Note that the time } \\
\text { that the component(s) are expected to be out of service is taken as a fraction } \\
\text { of the total number of hours per annum and incorporated in the calculation of } \\
\text { P(f) }\end{array}$ \\
\hline
\end{tabular}

Determining the additional amount of energy that can be expected to be supplied to consumers as a result of a capacity addition or reliability enhancement is an important part of quantifying the benefits of any proposed transmission system investment. The annual load duration curve is an integral part of this calculation.

\subsection{THE ANNUAL LOAD DURATION CURVE}

A chronological electricity demand curve for a typical day is shown in Figure 7.2a below. One can observe that electricity usage during the early hours of the morning is low, with the demand building up from $6 \mathrm{~h} 00$ to $9 \mathrm{~h} 00$ due to start-up of the business day. The load then flattens before the evening peak demand is experienced from $18 \mathrm{~h} 00$ to $20 \mathrm{~h} 00$ due to increasing residential or household usage 
as most people return home after work. The load decreases once again in the late evening as general activities taper off and users retire for the day.

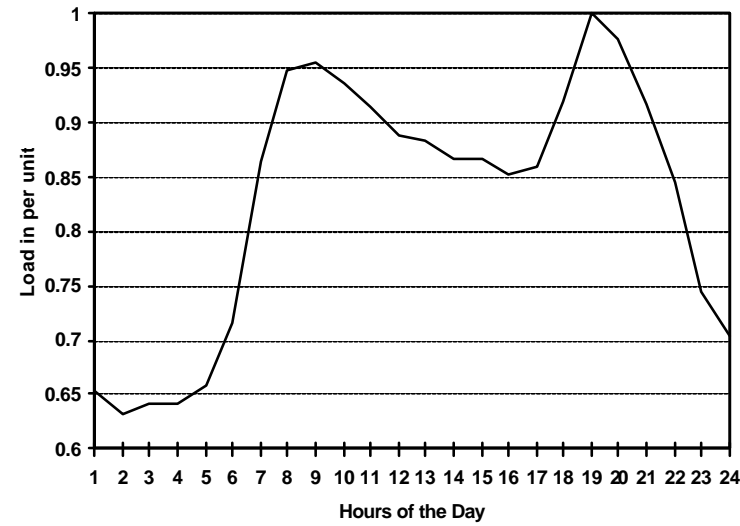

Figure 7.2a: Daily Chronological Electricity Demand

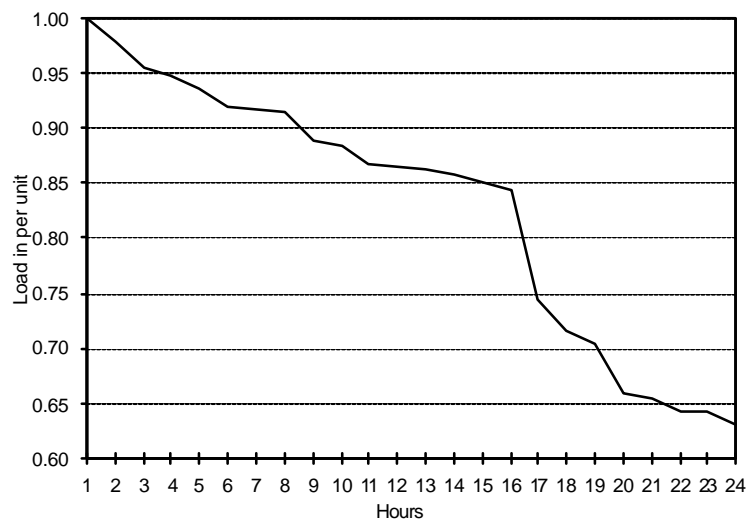

Figure 7.2b: Daily Load Duration Curve

The recorded data of the chronological load curve can be represented in an alternative manner as indicated in the adjacent Figure 7.2b above. The daily load duration curve is simply the same hourly demand readings arranged from the highest to the lowest values over the 24 hour period.

If the chronological electricity load data for each day of the year was accumulated and arranged from the highest to lowest values as before, one would derive a load duration curve similar to that illustrated in Figure 7.2b, except the horizontal axis would represent all 8760 hours of the year. A typical annual load duration curve is shown in Figure 7.3 below. The load duration curve enables one to determine the number of hours out of the total that the load (demand) exceeds a given level. This representation of the significant amount of load data is useful because it is necessary to evaluate annual costs against annual benefits (reduction in EENS per annum), in terms of the proposed investment appraisal model. In this context, the load duration curve is a cumulative probability distribution in the sense that if one were to pick a random time duration in that past year $\left(\mathrm{t}_{\mathrm{x}}\right)$ then the probability of demand having exceeded the level " $\mathrm{x}$ " for that time duration is $\mathrm{p}_{\mathrm{x}}$, where $\mathrm{p}_{\mathrm{x}}$ is equal to $t_{x}$ divided by 8760 hours (from Figure 7.3, one can observe that a probability of $42 \%$ corresponds to the time duration $t_{x}$ of approximately 3700 hours). From a system expansion planning point of view one would really be interested in the time duration $\left(\mathrm{t}_{\text {cap }}\right)$ or probability $\left(\mathrm{p}_{\text {cap }}=\mathrm{t}_{\text {cap }} \div 8760\right)$ that the forecasted electricity maximum demand will exceed the capacity (firm or otherwise) of the supply system. For example, the probability that the load will exceed 0,7 per unit is equal to $26 \%$ or, 2277 hours per annum (refer also to Figure 7.3). 


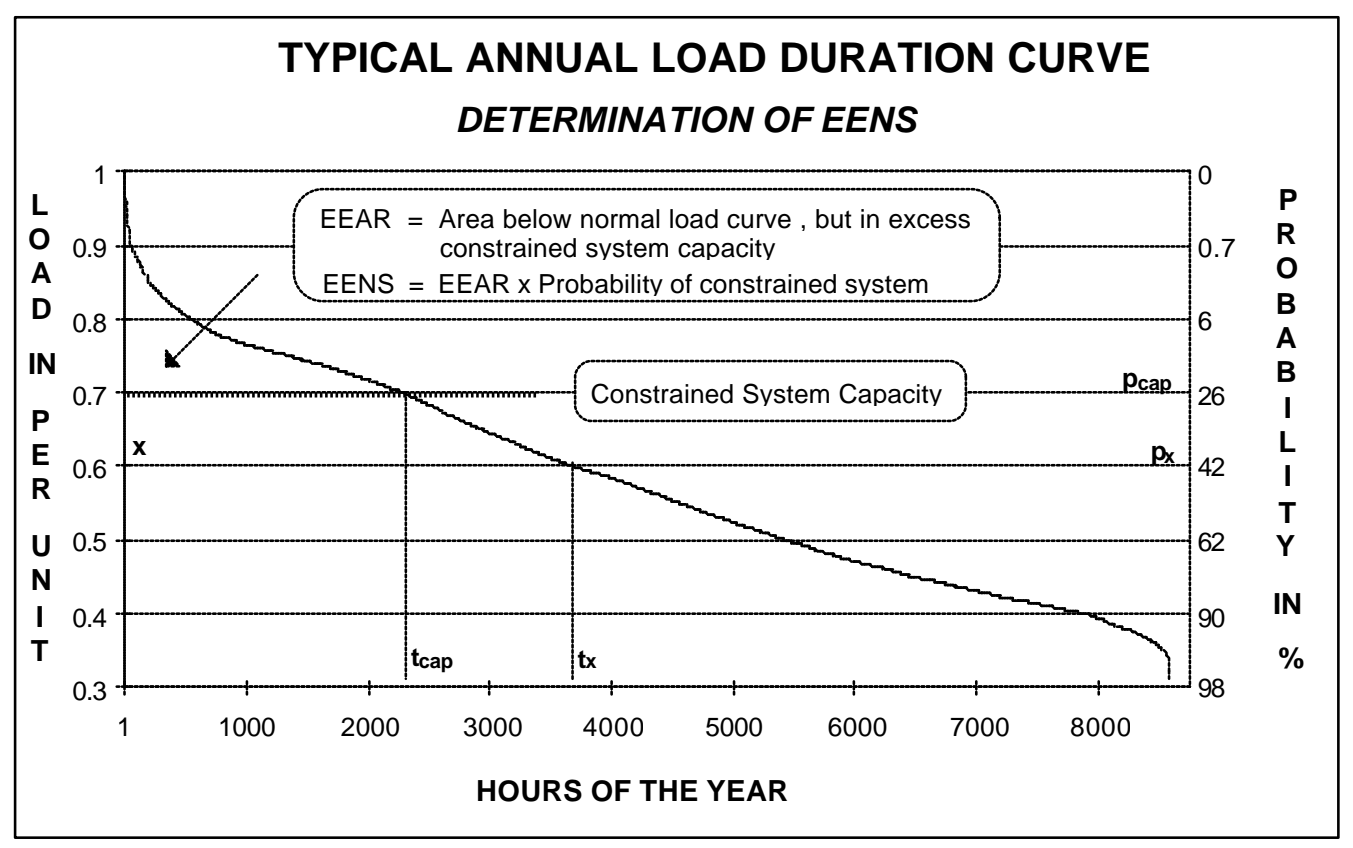

Figure 7.3: Typical Annual Load Duration Curve

If the annual load duration curve is truncated (some distance from the top) at that amount of load that the transmission system can supply when it is constrained (potential component outage condition) then, the amount of energy at risk of being interrupted in the truncated section can be determined by calculating the difference between the normal load duration curve (without any outage) and the truncated curve. This is equivalent to integrating the normal annual load duration curve from hour one to hour $\mathrm{t}_{\text {cap }}$ (the number of hours that the load demand exceeds that of the expected constrained transmission system capacity) and subtracting the energy that can in fact be supplied to the load ( $\mathrm{t}_{\text {cap }}$ $\mathrm{x}$ constrained transmission system capacity). However, it is not necessarily true that this expected energy at risk (EEAR) will be interrupted. A network component outage will have to occur (under relatively high load conditions) before any energy demanded by consumes is in fact not supplied. Therefore the expected energy not supplied (EENS) is equal to:

EENS $=$ EEAR $\times$ Probability that the existing system will be in a constrained condition .....(as per Equation 7.5)

In the next Section we will review the "value" of the reduction in EENS to electricity consumers in South Africa, to enable system planners to apply the above mentioned Equation (7.3) in the context of the proposed transmission infrastructure investment criterion.

\section{THE VALUE OF SERVICE RELIABILITY TO SOUTH AFRICAN ELECTRICITY CONSUMERS}

The "value-based" electricity network expansion planning described above is designed to match the level of investment in supply reliability with customers' reliability preferences. This approach assumes that customer preferences for service reliability can be measured. Customer interruption cost survey data provide the primary source of information on customer preference for reliability 
(Caves, Herriges and Windle[5]). Electricity consumers have widely varying preferences for price and reliability. At one end of the electricity market, one finds a relatively small number of customers who are willing to pay a premium to ensure that the quality of service to them is very high because they experience enormous costs when power supply reliability or quality problems occur. At the other end of the market spectrum are the vast majority of customers with less pressing needs. Evaluating investments in reliability according to the total cost of service requires information from across the entire spectrum of the market.

Empirical research was done to measure the electricity supply interruption costs incurred by residential and industrial customers in South Africa, using survey instruments that were developed by the Power Systems Research Group at the University of Saskatchewan, Canada (Wacker and Billinton[22]). Cost decomposition, willingness-to-pay and willingness-to-accept survey methods were the most important techniques used during the design of the aforementioned questionnaires. The residential and industrial customer classifications were selected in order to obtain probable lower- and upper-bound customer interruption cost estimates for use in the capital investment decision-making framework presented in this paper.

\subsection{RESIDENTIAL CUSTOMER SURVEY RESULTS}

The residential part of the survey was concerned with measuring the levels of hardship and discomfort as a result of interruptions and the customer willingness-to-pay to avoid such events. Respondents were asked to rate how problematic (or "undesirable") various interruption scenarios would be for their household. Residential respondents indicated that there are significant variations in the problems caused by various interruption scenarios when time of day, day of week, season of year and, duration and frequency are considered. A "degree of problems caused" or "impact of interruption" scale was also used to gauge the perceived variations. The results showed that problems increased as outage frequency increased. Winter was reported as the worst time for an interruption and summer as the least problematic. Outages after $17 \mathrm{~h} 00$ are less desirable than before $17 \mathrm{~h} 00$, whether it is weekdays or weekends. Some of the other results obtained are illustrated graphically in Figure 8.1.1 below.
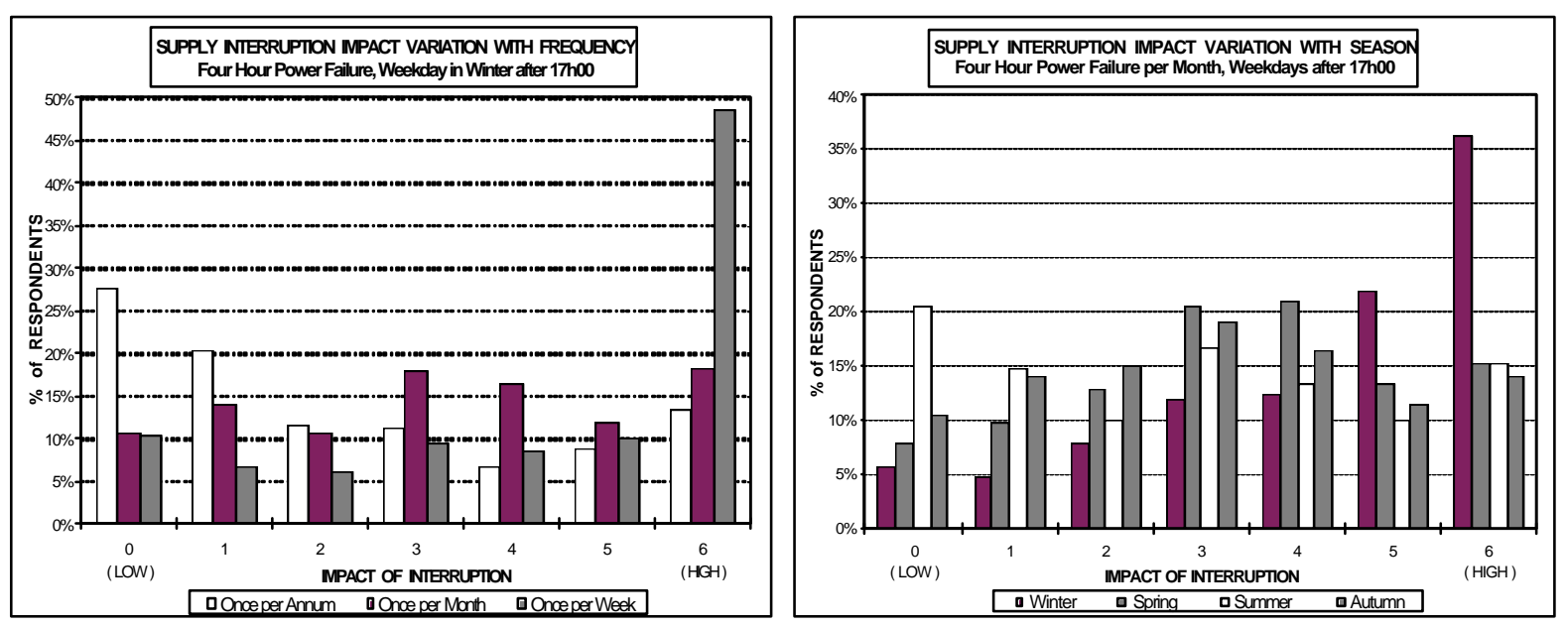

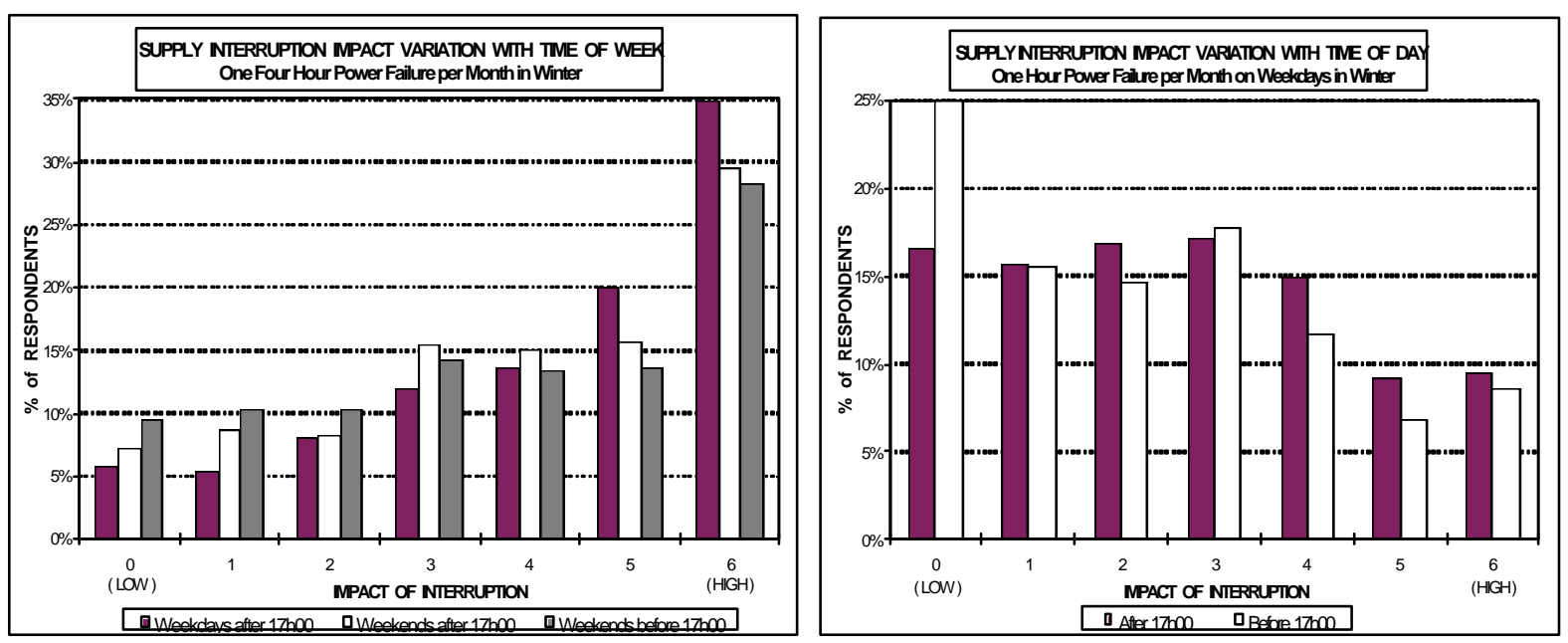

Figure 8.1.1: The Impact of Power Failures on Residential Electricity Consumers Under Various Outage Scenarios

An indirect costing question was considered as the primary cost assessment question in the residential questionnaire. Respondents were directed to suppose that they have been informed by their power company that power failures will occur after 17 h00 on winter weekdays but that the exact days or times are not known. They were then asked to predict which actions their household might take in preparation for the outages, to reduce the adverse effects of regularly recurring electricity supply interruptions. The possible six actions and their associated costs (to rent or buy and operate or use) included: (i) make no preparations which costs nothing, (ii) Burn a candle which costs 10 cents per hour, (iii) use a gas light or paraffin pressure lantern at a cost of 80 cents per hour, (iv) use a small gas stove costing R2,00 per hour, (v) use a small petrol electricity generator which costs R13,00 per hour and, (vi) spend R25,00 to use a large petrol electricity generator for an hour.

"Action costs" were calculated based on the costs associated with the actions chosen. Table 8.1.1 below represents the various average costs obtained from the responses to this question. The first and second columns list the outage scenarios, while the third column shows the average total costs per interruption.

\begin{tabular}{|l|c|c|c|}
\hline OUTAGE SCENARIOS & $\begin{array}{c}\text { SUPPLY } \\
\text { OUTAGE } \\
\text { DURATION }\end{array}$ & $\begin{array}{c}\text { AVERAGE TOTAL } \\
\text { COST PER } \\
\text { INTERRUPTION } \\
\text { (in } \text { Rand })\end{array}$ & $\begin{array}{c}\text { COST PER UNIT } \\
\text { ENERGY } \\
\text { INTERRUPTED } \\
\text { (in } \text { Rand } \text { per } \boldsymbol{k} \text { Wh } \text { ) }\end{array}$ \\
\hline \multirow{2}{*}{$\begin{array}{l}\text { Once a Month, } \\
\text { Winter Weekdays, } \\
\text { after 17h00 }\end{array}$} & 20 minutes & 0,27 & 0,57 \\
\cline { 2 - 4 } & One hour & 1,61 & 1,14 \\
\cline { 2 - 4 } $\begin{array}{l}\text { Once a Year, } \\
\text { Winter Weekdays }\end{array}$ & 4 hours & 11,77 & 2,08 \\
\cline { 2 - 4 } & 8 hours & 25,34 & 2,24 \\
\cline { 2 - 4 } & 4 hours & 91,28 & 2,69 \\
\hline Once a Month, Summer & 4 hours & 228,23 & 3,37 \\
\hline
\end{tabular}




\begin{tabular}{|l|c|c|c|}
\cline { 2 - 4 } Weekdays, after $17 \mathrm{~h} 00$ & & & \\
\hline Once a Year, & 48 hours & 184,24 & 2,72 \\
Summer Weekdays & & 165,55 & 2,44 \\
\hline $\begin{array}{l}\text { Twice a Year, } \\
\text { Summer Weekdays }\end{array}$ & 24 hours each & & \\
\hline
\end{tabular}

Table 8.1.1: Average Total Customer "Preparatory Action” Costs per Interruption

\subsection{INDUSTRIAL CUSTOMER SURVEY RESULTS}

The objective of the industrial survey was to obtain cost of interruption information for electrical users involved in chemicals, metals, pulp \& paper and food \& beverage manufacture, transport, mining and other non-metallic mineral operations. Respondents were asked to identify the worst month, day of the week and time of the day for an outage to occur. Options such as: more than one "worst time", "all months the same", a week-end/week-day distinction and, irregularly occurring worst times were provided. The most frequently selected options for the industrial customer respondents were "All Months the Same" (62\%), "All Seven Days of the Week the Same" (61\%) and, "All Times of the Days and Night the Same" (41\% of all respondents). Customers were also asked if their operations were such that lost production (or service provided) could be made up once power is restored (or on days following the interruption), without overtime or the use of extra staff and/or production resources. The average responses (in percent) are recorded in Table 8.2.1 below.

\begin{tabular}{|l|c|c|c|c|}
\hline $\begin{array}{l}\text { OUTAGE } \\
\text { DURATION }\end{array}$ & $\begin{array}{c}\text { NOT AT ALL } \\
(\boldsymbol{\%})\end{array}$ & $\begin{array}{c}\text { PARTLY } \\
(\boldsymbol{\%})\end{array}$ & $\begin{array}{c}\text { MOSTLY } \\
(\boldsymbol{\%})\end{array}$ & $\begin{array}{c}\text { NOT REQUIRED } \\
(\boldsymbol{\%})\end{array}$ \\
\hline 1 Minute & 55 & 6 & 32 & 9 \\
\hline 20 Minutes & 64 & 10 & 22 & 6 \\
\hline 1 Hour & 73 & 8 & 14 & 5 \\
\hline 4 Hours & 86 & 9 & 5 & 0 \\
\hline 8 hours & 96 & 4 & 0 & 0 \\
\hline
\end{tabular}

Table 8.2.1: $\quad$ Ability to Make-up Lost Production Once Power is Restored After Supply Interruptions

The direct cost assessment questions requested respondents to calculate their costs based on the worst time for an interruption to occur to their organisation as established in previous questions. For the industrial sector, the possible effects included: production loss (during the interruption and any restart-up time required), overtime cost, raw material and finished product spoilage, damage to plant equipment, start-up cost (extra clean-up, maintenance check-ups, etc.), environmental damage cost and, any other unspecified costs. Respondents were directed to calculate the aforementioned production losses by estimating foregone profit. Foregone profit was defined as: selling price of product or service less expenses saved in labour, materials, energy and, scrap value of damaged product or other inputs to the interrupted process. They were instructed to not include any proportion of lost sales or production that could be made up at a later stage. 
In conjunction with being asked to estimate the total interruption cost and the contributing factors, respondents were also asked to estimate, for each suggested interruption duration, how long it would take to restart or restore production once power is restored. Table 8.2.2 below presents the average re-start times as well as the average costs calculated from the responses to the direct cost assessment questions.

\begin{tabular}{|c|c|c|c|c|}
\hline $\begin{array}{l}\text { DURATION } \\
\text { OF INTER- } \\
\text { RUPTION }\end{array}$ & $\begin{array}{c}\text { AVERAGE } \\
\text { RE-START } \\
\text { TIMES } \\
\text { (Once Power } \\
\text { is Restored) } \\
\\
\text { (in Hours) }\end{array}$ & $\begin{array}{c}\text { AVERAGE } \\
\text { TOTAL COST } \\
\text { PER } \\
\text { INTER- } \\
\text { RUPTION } \\
\text { (Rand Mill/Int.) }\end{array}$ & $\begin{array}{l}\text { AVERAGE } \\
\text { TOTAL COST } \\
\text { PER MAX. } \\
\text { DEMAND } \\
\text { INTER- } \\
\text { RUPTED } \\
(\text { Rand/kW) }\end{array}$ & $\begin{array}{c}\text { AVERAGE } \\
\text { TOTAL COST } \\
\text { PER UNIT } \\
\text { ENERGY } \\
\text { INTER- } \\
\text { RUPTED } \\
\text { (Rand/kWh) }\end{array}$ \\
\hline 2 seconds & 0,98 & 0,413 & 4,33 & 14687,59 \\
\hline 1 minute & 0,98 & 0,413 & 4,91 & 489,59 \\
\hline 20 minutes & 2,58 & 0,557 & 9,41 & 37,81 \\
\hline 1 hour & 3,60 & 1,464 & 17,02 & 18,65 \\
\hline 2 hours & 4,47 & 2,405 & 23,80 & 13,72 \\
\hline 4 hours & 10,66 & 2,991 & 32,70 & 10,16 \\
\hline 8 hours & 12,14 & 5,273 & 42,65 & 8,23 \\
\hline 24 hours & 13,76 & 7,697 & 74,26 & 4,98 \\
\hline
\end{tabular}

Table 8.2.2: Average Results of the Industrial Customer Re-start Times and Direct Costs Assessment Questions

In summary therefore, the results of the aforementioned survey indicated that the average value of electrical service reliability (during outages of typical duration) is R2,64 and R20,09 per kilowatthour unit of additional energy consumed, to South African residential and industrial customers respectively.

\section{CONCLUSION}

A number of convincing arguments (based on sound economic theory) in favour of considering customer interruption costs have been presented in this paper.

It is submitted that the investigation conducted will enable the operator of the bulk electricity transmission system in South Africa match the level of investment in reliability related infrastructure, with customers' reliability preferences. The utilisation of reliability worth concepts in electric power systems provides the opportunity to incorporate customer considerations in the design of the system.

Due to the fact that customers have distinct needs, a system with uniform power supply reliability (which, by and large, is the result when traditional deterministic least-cost investment planning is preferred), is not the most economic way to meet the individual needs. The full power of the costbenefit reliability approach using customer interruption costs will only be realized when utilities go 
beyond optimizing for the average consumer (Burns and Gross[4]). Information on customer interruption costs can be used by the utility to design a menu of reliability service options at different prices. This "un-bundling" of electric supply services would enable each customer to benefit by selecting the individual's preferred service option. The aim of formulating a cost-benefit analysis based on economic principles is to design a model that can assist in: (1) redressing over-investment in those systems whose reliability is considered highest whilst maintaining the appropriate reliability of supply to consumers; (2) justifying the provision of higher than normal reliability where such a level is required; (3) justifying costs of providing normal levels of reliability where such costs are considered high and; (4) providing a means for determining preferences between alternative proposals which are substantially similar in other respects (Kariuki and Allan[12]). In an increasingly competitive environment, the utility benefits by enhancing customer satisfaction and avoiding investments in excessive supply side resources. The objective of the proposed investment criterion is not to specify that utilities invest in reliability to the point that investments exactly offset customer losses. It is to ensure that utilities do not invest in reliability beyond that point and to provide for the consistent evaluation of proposed transmission infrastructure investments.

The economic concepts discussed in this article provide the opportunity for the bulk electricity transmission industry in South Africa to re-examine some of its basic philosophies and standards. It is believed that the transmission system operator need not impose or adhere to rigid standards but should instead provide customers with information relating to quality of supply, that is, reliability, availability and related costs. This requires a vision of a new future, an awareness that all products in the marketplace have variable quality and reliability and, that customers should have freedom of choice between them.

\section{REFERENCES}

[1] Allan R N and Billinton R, 1992. Probabilistic Methods Applied to Electric Power Systems - Are They Worth It? Power Engineering Journal. May : 121-129.

[2] Andrews C J, 1992. An End-Use Approach to Reliability Investment Analysis. Energy Economics. October : 248-254.

[3] Billinton R and Li W, 1994. Reliability Assessment of Electricity Power Systems Using Monte Carlo Methods. New York : Plenum Press.

[4] Burns S and Gross G, 1990. Value of Service Reliability. IEEE Transactions on Power Systems. 5 (No. 3). August : 825-834.

[5] Caves D W, Herriges J A and Windle R J, 1990. Customer Demand for Service Reliability in the Electric Industry: A Synthesis of the Outage Cost Literature. Bulletin of Economic Research. 42 (No. 2) : 79-115.

[6] Chen C-Y and Vella A, 1994. Estimating the Economic Costs of Electricity Shortages Using Input-output Analysis: The Case of Taiwan. Applied Economics. 26 (Iss. 1) : 1061-1069.

[7] Douglas J, 1986. The Value of Reliability. EPRI Journal. March : 4-11. 
[8] Dutkiewicz R K, 1991. The Cost of Electricity Shortage or Surplus in South Africa. Journal of Energy, R\&D in South Africa. February : 3-6.

[9] Gauld R A, 1994. Prioritising Spending. Transmission \& Distribution International. Third Quarter : 20-31.

[10] Heck F M, 1961. The Cost of Capital in Economic Studies. AIEE Transactions Part III (Power Apparatus and Systems). December : 775-785.

[11] Hobbs B F, Rouse B H and Hoog D T, 1993. Measuring the Economic Value of Demand-side and Supply Resources in Integrated Resource Planning Models. IEEE Transactions on Power Systems. 8 (No. 3). August : 979-987.

[12] Kariuki K K and Allan R N, 1996. Applications of Customer Outage Costs in System Planning, Design and Operation. IEE Proceedings - Generation, Transmission and Distribution. 143 (No. 4) July : 305-312.

[13] Khatib H, 1996. Financial and Economic Evaluation of Projects with Special Reference to the Electrical Power Industry. Power Engineering Journal. February : 42-54.

[14] Munasinghe M, 1984. Engineering-Economic Analysis of Electric Power Systems Planning. Proceedings of the IEEE. 72 (No. 4) : 424-461.

[15] Sanghvi A P and Limaye D R, 1979. Planning Future Electrical Generation Capacity Supply Interruption: A Decision Analysis of the Costs of Over- and Under-building in the US Pacific Northwest. Energy Policy. June : 102-116.

[16] Sanghvi A P, 1982. Economic Costs of Electricity Supply Interruption: US and Foreign Experience. Energy Economics. 4 (No. 3) : 180-198.

[17] Sanghvi A P, 1983. Optimal Electricity Supply Reliability Using Customer Shortage Costs. Energy Economics. April : 129-136.

[18] Sanghvi A P, 1990. Measurement and Application of Customer Interruption Costs/Value of Service for Cost-Benefit Reliability Evaluation: Some Commonly Raised Issues. IEEE Transactions on Power Systems. 5 (No. 4) November : 1333-1343.

[19] Stoll H G, 1989. Least-Cost Electric Utility Planning. New York : John Wiley \& Sons.

[20] United States, Department of Energy. 1996. The Electric Power Outages in the Western United States, July 2-3, 1996: Report to the President. Washington, DC : Government Printing Office : 1-32.

[21] Valtorta M and Manzoni G, 1986. Reliability Co-ordination in Electric Power Systems. International Conference on Large High Voltage Electric Systems, Paris, September : 1-8.

[22] Wacker G and Billinton R, 1989. Customer Cost of Electric Service Interruptions. Proceedings of the IEEE. 77 (No. 6) June : 919-930. 